\title{
2004 INDEX BY SUBJECT
}

A

accommodation establishments

A survey of bedbugs in short-stay lodges, 2004 15(11-12), 215-217

adolescents see also children

Promoting tobacco to the young in the age of advertising bans, 2004 15(5-6), 104-106

Adult Health Survey

Monitoring health behaviours and health status in New South Wales: release of the Adult Health Survey 2002, 2004 15(4), 63-67

advertising

Promoting tobacco to the young in the age of advertising bans, 2004 15(5-6), 104-106

arboviral diseases see also Barmah Forest virus infections;

Ross River virus infections

Population health aspects of mosquito-borne disease in New South Wales, 2004 15(11-12), 193-199

\section{B}

Barmah Forest virus see also arboviral diseases

Recent increases in the notification of Barmah Forest virus infections in New South Wales, 2004 15(11-12), 199-203

bedbugs

A survey of bedbugs in short-stay lodges, 2004 15(11-12), 215-217

C

capacity building

Capacity building infrastructure grants workshop, 2004 15(3), 38

children see also adolescents; child abuse; immunisation; infants; lead; schools

Measures taken in New South Wales to address obesity following the New South Wales Childhood Obesity Summit, 2004 15(4), 68-71

chlamydia

What can laboratory notifications tell us about chlamydia infection?, 2004 15(3), 33-37

cockroaches

Overview of the public health implications of cockroaches and their management, 2004 15(11-12), 208-211

conferences

Measures taken in New South Wales to address obesity following the New South Wales Childhood Obesity Summit, 2004 15(4), 68-71

D

data collection see also health status; notifications; surveys DROPS: an automated web-based system for the reporting of drug related health statistics in NSW, 2004 15(7-8), 131135

databases

Notifiable diseases database system: review and development strategy, 2004 15(1-2), 10-12

debridement

Fly larvae for wound management: a maggot makeover, 2004 15(11-12), 218-219

dengue fever see also arboviral diseases

The increase in presentations of dengue fever in New South Wales, 2004 15(11-12), 204-207 diabetes

Self-reported risk factors and management strategies used by people with diabetes mellitus identified from the 1997 and 1998 NSW health surveys, 2004 15(4), 57-62

diet and nutrition

Introducing the NSW Centre for Public Health Nutrition, 2004 15(4), 72

drug abuse see also alcohol; methadone treatment

DROPS: an automated web-based system for the reporting of drug related health statistics in NSW, 2004 15(7-8), 131135

Opiate overdose and health treatment options for opiate users in New South Wales, 1999-2002, 2004 15(7-8), 125-131

drug dependence

Managing nicotine dependence in NSW hospital patients, 2004 15(5-6), 98-101

E

economic issues

The social costs of smoking in Australia, 2004 15(5-6), 92-94

enteroviral diseases

Communicable enteric disease surveillance, NSW, 2000-2002, 2004 15(1-2), 18-22

\section{fact sheets}

Factsheet: Foodborne disease, 2004 15(1-2), 24

Factsheet: Light cigarettes, 2004 15(5-6), 111

Factsheet: Tobacco and Health - Supporting someone to stop smoking, 2004 15(7-8), 136-137

Tobacco and health factsheet: car and home smoke-free zone, 2004 15(9-10), 182-183

$\mathbf{F}$

flies

Fly larvae for wound management: a maggot makeover, 2004 $15(11-12), 218-219$

foodborne diseases see also specific diseases e.g. salmonella

A large outbreak of norovirus gastroenteritis linked to a catering company, New South Wales, October 2003, 2004 15(9-10), $168-171$

Communicable enteric disease surveillance, NSW, 2000-2002, 2004 15(1-2), 18-22

Factsheet: Foodborne disease, 2004 15(1-2), 24

Foodborne disease surveillance in New South Wales, 2004 $15(1-2), 1-2$

Foodborne disease surveillance in New South Wales: moving towards performance standards, 2004 15(1-2), 2-5

Foodborne disease surveillance needs in Australia: harmonisation of molecular laboratory testing and sharing data from human, animal and food sources, 2004 15(1-2), 13-17

Hepatitis 'A' outbreak associated with a Mothers' Day 'Yum Cha' meal, Sydney, 1997, 2004 15(1-2), 6-9

G

\section{gastroenteritis}

A large outbreak of norovirus gastroenteritis linked to a catering company, New South Wales, October 2003, 2004 15(9-10), $168-171$

grants

Capacity building infrastructure grants workshop, 2004 15(3), 38 
H

health behaviours

Continuous NSW Health Survey: quarterly report on health status, health behaviours and risk factors, 2004 15(5-6), $112-114$

Monitoring health behaviours and health status in New South Wales: release of the Adult Health Survey 2002, 2004 15(4), 63-67

health status

Continuous NSW Health Survey: quarterly report on health status, health behaviours and risk factors, 2004 15(5-6), $112-114$

Monitoring health behaviours and health status in New South Wales: release of the Adult Health Survey 2002, 2004 15(4), 63-67

hepatitis

Hepatitis 'A' outbreak associated with a Mothers' Day 'Yum Cha' meal, Sydney, 1997, 2004 15(1-2), 6-9

|

infants (babies) see also birth defects; children; SIDS

Release of the New South Wales Mothers and Babies Report 2002, 2004 15(4), 73-75

infectious diseases see also names of specific diseases and organisms; notifications

Communicable diseases report, NSW, for December 2003 and January 2004, 2004 15(3), 44-53

Communicable diseases report, NSW, for February 2004, 2004 15(4), 76-82

Communicable diseases report, NSW, for July and August 2004, 2004 15(9-10), 184-188

Communicable diseases report, NSW, for March and April 2004, 2004 15(5-6), 115-122

Communicable diseases report, NSW, for May-June 2004, 2004 15(7-8), 144-153

Communicable diseases report, NSW, for October and November 2003, 2004 15(1-2), 25-30

Communicable diseases report, NSW, for September-October 2004, 2004 15(11-12), 220-226

Year in Review: communicable disease surveillance, 2003, 2004 15(9-10), 157-167

insects see also cockroaches; flies; mosquitoes; vector-

borne diseases

Unwanted guests: the miseries, the dangers and the glorious future of biting insects and vector-borne diseases in New South Wales, 2004 15(11-12), 191-192

\section{Internet}

DROPS: an automated web-based system for the reporting of drug related health statistics in NSW, 2004 15(7-8), 131135

\section{L}

\section{laboratories}

Foodborne disease surveillance needs in Australia: harmonisation of molecular laboratory testing and sharing data from human, animal and food sources, 2004 15(1-2), $13-17$

legislation see also specific legislation e.g. Public Health Act

Litigation and its current role in tobacco regulation in Australia, 2004 15(5-6), 102-103
M

management strategies

Self-reported risk factors and management strategies used by people with diabetes mellitus identified from the 1997 and 1998 NSW health surveys, 2004 15(4), 57-62

meningococcal disease

Meningococcal disease in New South Wales, 1991-2002, 2004 15(3), 39-43

mortality

Opiate overdose and health treatment options for opiate users in New South Wales, 1999-2002, 2004 15(7-8), 125-131

Year in Review: communicable disease surveillance, 2003, 2004 15(9-10), 157-167

mosquitoes see also insects

Population health aspects of mosquito-borne disease in New South Wales, 2004 15(11-12), 193-199

mothers

Release of the New South Wales Mothers and Babies Report 2002, 2004 15(4), 73-75

$\mathbf{N}$

nicotine see also smoking

Factsheet: Tobacco and Health - Supporting someone to stop smoking, 2004 15(7-8), 136-137

Managing nicotine dependence in NSW hospital patients, 2004 15(5-6), 98-101

Norwalk-like viruses

A large outbreak of norovirus gastroenteritis linked to a catering company, New South Wales, October 2003, 2004 15(9-10), $168-171$

notifications see also data collection

A review of Salmonella surveillance in New South Wales, 1998-2000, 2004 15(9-10), 178-181

Notifiable diseases database system: review and development strategy, 2004 15(1-2), 10-12

What can laboratory notifications tell us about chlamydia infection?, 2004 15(3), 33-37

Year in Review: communicable disease surveillance, 2003, 2004 15(9-10), 157-167

0

obesity

Measures taken in New South Wales to address obesity following the New South Wales Childhood Obesity Summit, 2004 15(4), 68-71

opiates

Opiate overdose and health treatment options for opiate users in New South Wales, 1999-2002, 2004 15(7-8), 125-131

$\mathbf{P}$

passive smoking

A report on the NSW Tobacco Action Plan 2001-2004, 2004 15(5-6), 95-98

Current tobacco smoking by the NSW population and the consequences for health, 2004 15(5-6), 87-91

Litigation and its current role in tobacco regulation in Australia, 2004 15(5-6), 102-103

Tobacco and health factsheet: car and home smoke-free zone, 2004 15(9-10), 182-183 


\section{performance standards}

Foodborne disease surveillance in New South Wales: moving towards performance standards, 2004 15(1-2), 2-5

\section{public health see also conferences}

Introducing the NSW Centre for Public Health Nutrition, 2004 15(4), 72

Tobacco control in Australia: victims of our past success?, 2004 15(5-6), 85-87

\section{R}

\section{risk factors}

Continuous NSW Health Survey: quarterly report on health status, health behaviours and risk factors, 2004 15(5-6), $112-114$

Risk factors for sporadic Salmonella birkenhead infection in Queensland and northern New South Wales: a case control study, 2004 15(9-10), 172-177

Self-reported risk factors and management strategies used by people with diabetes mellitus identified from the 1997 and 1998 NSW health surveys, 2004 15(4), 57-62

\section{S}

\section{salmonella see also foodborne diseases}

A review of Salmonella surveillance in New South Wales, 1998-2000, 2004 15(9-10), 178-181

Risk factors for sporadic Salmonella birkenhead infection in Queensland and northern New South Wales: a case control study, 2004 15(9-10), 172-177

smoking see also passive smoking; tobacco sales; nicotine

A report on the NSW Tobacco Action Plan 2001-2004, 2004 15(5-6), 95-98

Current tobacco smoking by the NSW population and the consequences for health, 2004 15(5-6), 87-91

Factsheet: Light cigarettes, 2004 15(5-6), 111

Factsheet: Tobacco and Health - Supporting someone to stop smoking, 2004 15(7-8), 136-137

Litigation and its current role in tobacco regulation in Australia, 2004 15(5-6), 102-103

Managing nicotine dependence in NSW hospital patients, 2004 15(5-6), 98-101

The 2004 United States Surgeon General's Report: The Health Consequences of Smoking, 2004 15(5-6), 107

The impact of low-tar cigarettes, 2004 15(5-6), 108-110

The social costs of smoking in Australia, 2004 15(5-6), 92-94

Tobacco and health factsheet: car and home smoke-free zone, 2004 15(9-10), 182-183

Tobacco control in Australia: victims of our past success?, 2004 15(5-6), 85-87

socioeconomic factors

The social costs of smoking in Australia, 2004 15(5-6), 92-94

\section{$\mathbf{S}$}

surveys see also data collection

Communicable enteric disease surveillance, NSW, 2000-2002, 2004 15(1-2), 18-22

Current tobacco smoking by the NSW population and the consequences for health, 2004 15(5-6), 87-91

Foodborne disease surveillance in New South Wales, 2004 $15(1-2), 1-2$

Foodborne disease surveillance needs in Australia: harmonisation of molecular laboratory testing and sharing data from human, animal and food sources, 2004 $15(1-2), 13-17$

T

ticks

Review of public health advice about ticks, 2004 15(11-12), 212-215

tobacco sales see also smoking

A report on the NSW Tobacco Action Plan 2001-2004, 2004 15(5-6), 95-98

Litigation and its current role in tobacco regulation in Australia, 2004 15(5-6), 102-103

Promoting tobacco to the young in the age of advertising bans, 2004 15(5-6), 104-106

The impact of low-tar cigarettes, 2004 15(5-6), 108-110

Tobacco control in Australia: victims of our past success?, 2004 15(5-6), 85-87

tuberculosis

Epireview: Tuberculosis in New South Wales, 1991-2002, 2004 15(7-8), 138-143

$\mathbf{U}$

United States

The 2004 United States Surgeon General's Report: The Health V Consequences of Smoking, 2004 15(5-6), 107

vector-borne diseases see also arboviral diseases

Population health aspects of mosquito-borne disease in New South Wales, 2004 15(11-12), 193-199

Recent increases in the notification of Barmah Forest virus infections in New South Wales, 2004 15(11-12), 199-203

Review of public health advice about ticks, 2004 15(11-12), 212-215

Unwanted guests: the miseries, the dangers and the glorious future of biting insects and vector-borne diseases in New South Wales, 2004 15(11-12), 191-192

W

wounds see also injuries and accidents

Fly larvae for wound management: a maggot makeover, 2004 15(11-12), 218-219 
2003 INDEX BY AUTHOR

A

Ashwell M $200415(1-2), 6$

Ayyar A 200415 (9-10), 172

B

Baker D 200415 (4), 63

Bartlett M 200415 (1-2), 10

Bauman A 200415 (4), 57

Beard F 200415 (4), 73 $200415(9-10), 172$

Beer I $200415(1-2), 6$

Birrell F 200415 (9-10), 172

Burns T 200415 (9-10), 168

C

Campbell E 200415 (5-6), 98

Capon A 200415 (9-10), 168

Carey V 200415 (11-12), 212

Chapman $\mathbf{S}$ 200415 (5-6), 85

Christensen A 200415 (7-8), 138

Collins D 200415 (5-6), 92

Cook S 200415 (7-8), 125

Corbett S 200415 (11-12), 191

D

Dalton C 200415 (1-2), 1 200415 (1-2), 2

Develin L 200415 (4), 68

Doggett $S$ 200415 (11-12), 193

Doyle B 200415 (9-10), 168

Dwyer D

E 200415 (11-12), 199

Eyeson-Annan M $200415(4), 63$ 200415 (5-6), 112
F

Ferson MJ 200415 (1-2), 6

Freund M 200415 (5-6), 98

G

Geary M 200415 (11-12), 218

Gray J 200415 (7-8), 125

H

Hailstone $\mathrm{S}$ 200415 (5-6), 95

Hamilton I 200415 (9-10), 168

Harvey $L$ 200415 (11-12), 199

Hogan D

$$
200415 \text { (3), } 39
$$

Hort K 200415 (11-12), 191

Hueston L 200415 (11-12), 204

I

Indig D

200415 (7-8), 125

200415 (7-8), 131

Irvine $\mathbf{K}$

200415 (5-6), 112

J

Jauncey M 200415 (7-8), 131

K

Kaldor J 200415 (7-8), 131

King L 200415 (4), 72

Kirk M 200415 (1-2), 13

Kolbe T 200415 (9-10), 168

L

Lapsley $\mathbf{H}$ 200415 (5-6), 92

Lawrence V 200415 (3), 33

Lee D 200415 (1-2), 6

Liberman J 200415 (5-6), 102

Lui B

200415 (3), 33
M

Maywood P 200415 (3), 33

McAnulty J

200415 (1-2), 6 200415 (1-2), 18 200415 (3), 39 200415 (7-8), 138 200415 (9-10), 168

McGrath D 200415 (7-8), 125

Merritt T 200415 (9-10), 178

Miller $\mathbf{P}$ 200415 (11-12), 208 200415 (11-12), 215

Mitchell E 200415 (5-6), 87 200415 (5-6), 98

Mitchell JA 200415 (5-6), 95

Morgan G 200415 (9-10), 172

Musto J 200415 (9-10), 168

N

Naylor C 200415 (3), 38

Neville $\mathbf{L}$ 200415 (1-2), 18 200415 (4), 57

0

O'Connor B 200415 (7-8), 138

P

Paul C 200415 (5-6), 98

Persson L 200415 (1-2), 10

Peters B

200415 (11-12), 208 200415 (11-12), 215

R

Russell R 200415 (11-12), 218

Ryan N 200415 (11-12), 215

$\mathrm{S}$

Sanders J 200415 (5-6), 87

Sanders S 200415 (5-6), 104 
Sathanandan D

200415 (3), 33

Soulos G

200415 (5-6), 104

Staff $M$

200415 (3), 33

Stafford R

200415 (9-10), 172

Stewart B

200415 (5-6), 108

T

Taylor L

200415 (4), 73

Telfer B

200415 (9-10), 168

Terry J

200415 (9-10), 172

Torres M

200415 (11-12), 212

U

Unicomb $\mathbf{L}$

200415 (9-10), 178

W

Wiggers J

200415 (5-6), 98

Wolfenden $\mathrm{L}$

200415 (5-6), 98 